\title{
The Dissemination of Vocational Technology and Influencing Factors under Modern Apprenticeship
}

\author{
Kai $\mathrm{Wu}^{1,2}$, Fan $\mathrm{Xu}^{3}$ \\ ${ }^{1}$ College of Management and Economics, Tianjin University, Tianjin, China \\ ${ }^{2}$ School of Economics and Management, Tianjin University of Science and Technology, Tianjin, China \\ ${ }^{3}$ College of Civil Engineering, Northeast Forestry University, Harbin, China \\ Email: laokaino1@163.com
}

How to cite this paper: $\mathrm{Wu}, \mathrm{K} .$, \& $\mathrm{Xu}, \mathrm{F}$. (2021). The Dissemination of Vocational Technology and Influencing Factors under Modern Apprenticeship. Open Journal of Social Sciences, 9, 32-42. https://doi.org/10.4236/jss.2021.96004

Received: May 12, 2021

Accepted: June 6, 2021

Published: June 9, 2021

Copyright $\odot 2021$ by author(s) and Scientific Research Publishing Inc. This work is licensed under the Creative Commons Attribution International License (CC BY 4.0).

http://creativecommons.org/licenses/by/4.0/ (c) (i) Open Access

\begin{abstract}
In order to cope with the shortage of technical personnel, the development of modern vocational education has become a major strategy. Based on schoolenterprise integration, modern apprenticeship is an important part of vocational education system. According to teaching practice and the theory of knowledge dissemination, this paper divides the process of vocational technology dissemination into five stages: theoretical learning, attention, retention, reproduction and motivation. With the theoretical analysis, business interview, and induction, the influencing factors of technology dissemination are summarized into six levels: disseminator, learners, knowledge characteristics, communication media, organizational environment, and external environment. The conclusion extends the theory of knowledge dissemination, and provides theoretical basis and practical guidance for the training of skilled talents, and for exploring the reform of modern apprenticeship.
\end{abstract}

\section{Keywords}

Technology Dissemination, Modern Apprenticeship, Tacit Knowledge, Influencing Factors

\section{Introduction}

Economic structural adjustment leads to the obsolescence of some technologies and expands novel jobs that need new technologies (Thisse \& Zenou, 2000). The shortage of skilled labor is one of the most significant concerns for industry (Kim et al., 2020), and it is already being felt by some companies (87\%) (Rahim et al., 2016). Even with the trend of intelligent manufacturing, robots can replace 
manual operation. In some key technical detail, it still needs advanced technicians to complete tasks manually. The development of vocational education is a necessary measure to alleviate the coexistence of "unemployment and labor shortage".

Modern vocational education was originated in the 1970s (Guichard, 2001), which has appeared in Britain, the United States, Germany, Australia and other countries. In addition to theoretical knowledge, it pays more attention to skills training. However, there are some problems in vocational education, such as single assessment method, lack of teaching plan and practical applicability. These problems lie in the decoupling of specialty setting and industrial demand, the inconsistency between curriculum content and professional standards, especially the lack of practical ability of students, which makes them difficult to cope with industrial development. Based on the integration of school and enterprise, the modern apprenticeship is an important part of the vocational education, which can better coordinate the relationship between vocational education and industrial demand. Generally, the modern apprenticeship system is still in the exploratory stage, especially some students only engaged in assembly line production tasks, and become cheap labor. How to improve students' vocational skills is an important problem.

Traditional apprenticeship is a mode of technology dissemination between master works and apprentices in workshops. Modern apprenticeship is a cooperative education system which combines traditional apprenticeship with modern school education. This paper focuses on vocational technology dissemination. Based on practical observation and theoretical analysis, it summarizes the process of vocational technology dissemination: Take theoretical learning as the starting point, through the stages of attention, retention, reproduction and motivation. Under cooperation between school and enterprise, each stage adopts different teaching contents, sites and assessment methods to consolidate the effect of vocational technology. Through theoretical analysis, practical interview, induction and sorting, this paper further sums up the influencing factors about technology dissemination. The influencing factors include learner, disseminator, knowledge characteristics, communication media, organizational environment and industry environment, with a total of 20 influencing factors. According to the characteristics of knowledge dissemination, combined with relevant theories, this paper analyzes the process and influencing factors of vocational technology dissemination, so as to provide theoretical reference and practical help for the reform of modern apprenticeship system.

\section{Literature Review}

Technology is used to accomplish a specific task, and is consistent with a method. Therefore, it is in harmony with an approach as well (Anthony, 1963). Professional technology is combination of knowledge that transforms resources into industrial products and consumer goods, which contains a large number of procedural knowledge such as skills, experience and know-how in business links. 
For knowledge dissemination, scholars have done some research on communication subject, process, motive force, influencing factors, evaluation indicators and so on. The results can be summarized into three directions: one is the general theoretical research based on abstract organization level, the other is the empirical research based on certain specific application level, and the third is the empirical research about the influencing factors of knowledge dissemination.

\subsection{Research on Knowledge Dissemination}

Some scholars explore the process of knowledge dissemination. For example, knowledge transfer is defined as a process of knowledge creation, application, mobilization, exchange, search and transformation (Awang et al., 2009). An organization learns from direct experience for analyzing, coding, storing and retrieving information (Levitt \& March, 1988). Knowledge transfer was found to be associated with knowledge context, relationship, recipient, and transfer activity (Cummings \& Teng, 2003). The technology-organization-environment framework was summarized for diffusion of innovations and technology adoption (Baker, 2012). Through the analysis of organizational and technological literature, Gilbert and Cordey-Hayes presented a conceptual model for understanding the processes of knowledge transfer (Gilbert \& Cordey-Hayes, 1996). These documents basically focus on the disseminators, learners, communication environment and knowledge characteristics in the process of knowledge communication, which provide a theoretical basis for analysis of the vocational technology dissemination. These achievements regard knowledge as a whole, while vocational knowledge includes both explicit knowledge to explain the theory, and tacit knowledge to guide the operation. Vocational technology focuses more on practical operation, and tacit knowledge is the key point in communication. Therefore, based on the traditional literature, this paper takes into account the characteristics of explicit and tacit knowledge to analyze the dissemination process of vocational technology.

Some scholars have carried out research on knowledge dissemination based on specific application scenarios. Such as online knowledge exchange platform (Kuang et al., 2019), technological knowledge exchange network in regional cluster (Ahn \& Kim, 2019), Knowledge transfers in large scale infrastructure projects (Aerts et al., 2017), a longitudinal study of university knowledge exchange (Zhang, 2018) et al. Based on these results, we can conclude that knowledge dissemination is a complex process, which requires a good interactive environment, the incentive mechanism for participants, and the optimization of knowledge dissemination process. These specific application scenarios provide a reference for the analysis of vocational technology dissemination.

There are also some scholars who study the influencing factors of knowledge dissemination from different perspectives, such as from collaborative innovation network (Xie et al., 2016), buyer-supplier relationship (Balboni et al., 2017), untraded interdependencies-knowledge exchange (Tallman et al., 2004), knowledge transfer between group members with equal or different status (Haesebrouck et 
al., 2018), and organizational culture on knowledge transfer (Wei \& Miraglia, 2017). Above the research, we can see that there are many factors affecting knowledge dissemination, and the effects of each factor are different roles (Ciabuschi et al., 2017). These results provide the basis for the analysis of influencing factors of vocational technology dissemination. Based on the conclusions, this paper sums up the influencing factor.

\subsection{Research on Tacit Knowledge}

Vocational technology contains a lot of tacit knowledge such as skills and know-how, which needs to be spread in practice face by face. In 1958, according to the difficulty of knowledge expression, Austrian scholar Michael Polanyi divides knowledge into explicit knowledge and tacit knowledge. The tacit knowledge, which is difficult to express in writing, needs to be spread through demonstration and communication between people. Some scholars have expanded the research on tacit knowledge, such as Ikujiro Nonaka, who studied the dynamic process in which an organization creates, maintains and exploits knowledge (Nonaka et al., 2000). Some scholars have studied the characteristics of tacit knowledge, including tacit knowledge dissemination model (Muñoz et al., 2015; Zhu et al., 2016), the influence of organizational culture on tacit knowledge sharing behavior (Suppiah \& Sandhu, 2011), and Knowledge increment linear model (Cowan \& Jonard, 2004; Lin \& Li, 2010). Other literatures focus on the communication effect of tacit knowledge, such as the impact on innovation performance (Pérez-Luño et al., 2019), the evaluation of transformation effect (Joia \& Lemos, 2010), exploring the impact of affect-based and cognition-based trust of co-workers on the willingness to share and use tacit knowledge (Holste \& Fields, 2010), and evaluate tacit knowledge sharing in determining innovation capability of an organization (Ganguly et al., 2019). The above literature studies the common characteristics of tacit knowledge. Vocational technology embodies the tacit knowledge of skills such as methods, skills, experience and know-how. At the same time, the vocational technology also presents certain particularity. Particularly, the knowledge embedded in the business is not easy to break through organizational boundaries, and its transfer is limited by the established environment. Although Nonaka's SECI model theory proposes that explicit knowledge and tacit knowledge can be transformed into each other [21], vocational technology focuses more on practical operation. For example, in the manufacturing industry, learners need repeated training in turning, fitter, riveter, electrician, welder and other technologies. Some technologies must be operated with specific raw materials under the production equipment. At the same time, high scrap cost, technical confidentiality and safety requirements limit the spread of technology.

With the development of vocational technology, tacit knowledge, rather than explicit knowledge, has gradually become the key point of competition. The methods, skills, experience and know-how embodied in the tacit knowledge 
need to be spread between teacher and student face by face. Based on teaching practice and observation learning theory, the third part of this paper summarizes the basic process of vocational technology dissemination. The fourth part analyzes the influencing factors. The fifth part puts forward suggestions for the development of modern apprenticeship.

\section{The Process of Professional Technology Dissemination}

\subsection{The Practical Situation for Technology Dissemination}

The modern apprenticeship is performed through the deep cooperation between schools and enterprises, and the joint teaching of teachers and master workers. Modern apprenticeship employs enterprise experts to participate in the training, recommend excellent technical personnel and management talents of enterprises as part-time teachers; import enterprise scientific research and production bases, and establish a comprehensive experimental training center. All of these can provide a basis for vocational technology dissemination.

\subsection{The Vocational Technology Dissemination under Modern Apprenticeship}

Observational learning is a concept put forward by Albert Bandura in the Social Learning Theory. It described a process to imitate others' behavior and obtained information and knowledge. Bandura believes that observational learning can be divided into four processes: attention, retention, reproduction and motivation. The application of this theory to apprenticeship has its applicability: Observation Learning emphasizes the imitation and experience of demonstration behavior to obtain technologies. The vocational technology dissemination is the specific application of observation learning theory. Based on the Observational Learning theory, combined with the actual situation of technology dissemination, this paper summarizes the process of vocational technology dissemination.

Observation learning theory is a summary of behavior imitation, which is suitable to express the technology dissemination process of traditional apprenticeship. However, modern apprenticeship is based on the integration of schools and enterprises, which is different from Observation learning in two aspects. 1) Modern apprenticeship takes theoretical knowledge as the starting point, professional theory is taught by teachers in the form of explicit knowledge, and practical operation is displayed in the form of tacit knowledge. In the modern apprenticeship, theory and practice complement each other. The theory enables learners to master the technical principles. The specific operation of the practice can make learners understand the operation skills and truly apply what they have learned. Any type of vocational technology is a comprehensive application of a series of theory. "Theory guides practice", so theory learning is an essential part. Traditional apprenticeship often ignores the guiding role of theory. For example, the technical staff of digital control need to understand the principles of mechanical drawing, read and compile processing technology of machine; be 
familiar with computer programming, compile NC machine tool processing program; be proficient in mechanical and electrical principles, and master the design, installation, debugging and maintenance of machinery and equipment. Such technology integrates multi-disciplinary theory. 2) The teaching site is transformed from school classroom to training bases and production workshop. Traditional apprenticeship only spreads technology in enterprises or workshops. In the context of modern apprenticeship, technology spreads in two situations. One is school or training institution, with theoretical teaching as starting point and practice teaching as auxiliary, and the other is enterprise or workshop, which focuses on the practical application with "learning by doing". Above the analysis, based on teaching practice and observation learning theory, the process of vocational technology dissemination is divided into five stages: theoretical learning, attention, retention, reproduction and motivation, as shown in Figure 1.

Theoretical learning is the starting point of technology dissemination, which is carried out through classroom teaching. "Attention" is the corresponding experimental operation of classroom teaching. Classroom teaching or experimental operation can belong to the same course, which is a combination of "theory + practice". "Attention" includes teacher's demonstration and student's operation, which is a "face by face" learning period. Students observe and experience the technical details. "Retention" is a comprehensive design of several related courses. After this process, students can complete a work independently. The difference between "Attention" and "Retention" is that the former is mainly based on teacher's demonstration, supplemented by students' operation, while the latter requires students to complete independently, supplemented by teachers' necessary guidance. The former is a learning of a single course, while the latter is a synthesis of several related courses. "Reproduction" is to act according to the memory, apply the technology to the enterprise production, or simulate the actual process of enterprise production. This process can be realized in the production site by internship. "Motivation" is to constantly improve the original technology, form new technique and knowledge. Students participate in competitions or apply for patent at this stage. Any technology is not immutable; it is constantly improved under the painstaking research of practitioners. At this stage, people are constantly improving the raw materials, product design, production process and quality, summarizing new experience, upgrading to new

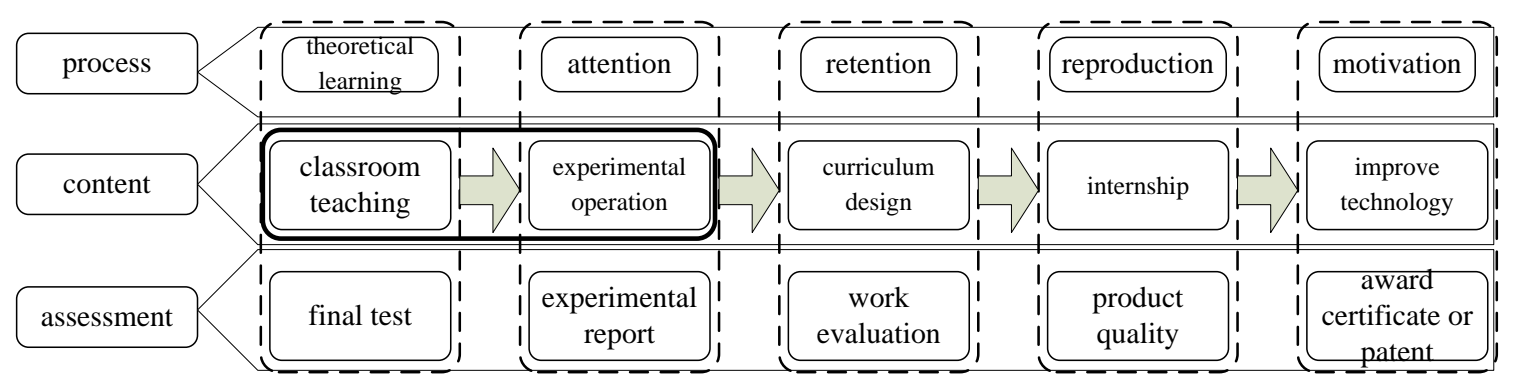

Figure 1. The process of vocational technology dissemination under modern apprenticeship. 
knowledge, and improving the original theoretical system. Therefore, the "Motivation" is not only the improvement of behavior, but also the theoretical innovation of technology.

Through the field research of application-oriented majors in colleges and universities, vocational technology dissemination basically follows the mode of "theoretical teaching + curriculum experiment + comprehensive curriculum design + Internship". Some schools can guide students to participate in various competitions or apply for patents. Although the process is basically the same, teaching facilities, field equipment, and the level of teachers and technicians have different effects on knowledge dissemination. Therefore, after clarifying the process of vocational technology dissemination, it needs further study the influencing factors of vocational technology dissemination.

\section{Analysis on the Influencing Factors of Vocational Technology Dissemination}

Traditional apprenticeship takes enterprises or workshops as the main venues, while modern apprenticeship takes place in classrooms, laboratories, training bases, enterprises, workshops and so on. The same of traditional apprenticeship and modern apprenticeship is that tacit knowledge such as skills, methods, experience and know-how in vocational technology needs to be tested by practice, explored gradually in production activities and applied to production. Next, this paper focuses on the influencing factors of knowledge dissemination in production practice.

After the analysis of vocational technology dissemination, it is necessary to further analyze the influencing factors through three steps: theoretical analysis, field interview and induction. 1) Theoretical analysis. In addition to observational learning theory, the author reviews and collates the relevant theories of knowledge and technology dissemination, such as Organizational learning theory, Social cognitive theory, Social learning theory, Technology-organizationenvironment framework, Organizational knowledge creation, Technology acceptance model, and so on. On the basis of these classic theories, 37 influencing factors are preliminarily sorted out. These results come from the theory and literature, lack of practical guidance. Next, through field interviews, the authors understand the professional views on technology dissemination. 2) Interview. The selected interviewees include the engineers who are responsible for guiding students to operate machine in factories, and the manufacturing technicians from enterprises in Tianjin city. The authors solicit professional opinions, and listen to the story of the workshop. After the interview, it is expanded to 43 influencing factors. 3) Induction. The author's team discussed and evaluated many times, combined the similar factors, removed the controversial factors, and finally summarized to six levels: disseminator, learner, Knowledge characteristics, Communication media, organizational environment and external environment, with a total of 20 influencing factors (Table 1). 
Table 1. Influencing factors vocational technology dissemination.

\begin{tabular}{|c|c|c|c|}
\hline main level & influence factor & main level & influence factor \\
\hline \multirow{3}{*}{ Disseminator } & Technical capability & \multirow{3}{*}{ Learner } & Technical level \\
\hline & Willingness to teach & & Physical quality \\
\hline & Moral image & & Willingness to learn \\
\hline \multirow{3}{*}{$\begin{array}{l}\text { Knowledge } \\
\text { characteristics }\end{array}$} & Complexity level & \multirow{3}{*}{$\begin{array}{l}\text { Communication } \\
\text { media }\end{array}$} & Explicit media \\
\hline & Function level & & Technology sharing platform \\
\hline & Standardization degree & & Machine equipment \\
\hline \multirow{4}{*}{$\begin{array}{l}\text { Organizational } \\
\text { environment }\end{array}$} & Interpersonal relationship & \multirow{4}{*}{$\begin{array}{c}\text { External } \\
\text { environment }\end{array}$} & Personnel mobility \\
\hline & Training plan & & Inter Organizational linkages \\
\hline & Organizational culture & & Industry Association support \\
\hline & $\begin{array}{l}\text { Reward and punishment } \\
\text { mechanism }\end{array}$ & & Policy support \\
\hline
\end{tabular}

\section{Conclusion}

Modern apprenticeship is not only different from the traditional apprenticeship which mainly focuses on workshop training, but also different from the traditional education of school training which lays stress on theoretical teaching. It is a talent training of cooperation between schools and enterprises and the combination of theory and practice. At present, the modern apprenticeship system is still in the exploratory stage. Under such background, based on the development demand and theoretical basis, this paper studies the vocational technology dissemination from such backgrounds. Firstly, economic development is facing the skilled talent shortage. Vocational training is a necessary measure to solve the shortage of technical talent. Secondly, from a theoretical view: technology dissemination belongs to knowledge communication, especially tacit knowledge communication. However, vocational technology dissemination has certain particularity, which depends on specific production equipment, and takes into account the requirements of scrap cost of raw materials, technical confidentiality and production safety. These characteristics make the vocational technology dissemination different from the tacit knowledge communication. It is necessary to expand the existing theoretical research. This paper discusses the process of vocational technology dissemination and its influencing factors, and provides theoretical basis and practical guidance for the training of skilled talents.

This paper has two aspects of practical significance: 1) it objectively summarizes the process of technology dissemination, and provides theoretical guidance for the exploration of modern apprenticeship. According to the different stages of technology dissemination, the corresponding teaching contents, methods, venues and assessment criteria are adopted to promote technology dissemination. 2) Vocational technology is different from ordinary knowledge communication. It can be seen from the communication process that in addition to the theoretical learning stage, the attention, retention, reproduction and motivation 
stage all need learners to practice deeply and gradually master the technology in the field practice. Therefore, vocational technology needs to be spread in two situations, adhering to the cooperation between schools and enterprises, and the combination of theory and practice, which is the talent training mode advocated by modern apprenticeship. From the perspective of school, technical training should be connected with enterprise practice; from the perspective of enterprises, under the premise of ensuring normal production, strengthening the practice training becomes the key to the spread of vocational technology, which is a practical solution to modern apprenticeship exploration.

\section{Acknowledgements}

We would like to acknowledge financial support from Tianjin Philosophy and Social Science Planning Project (Grants No. TJGL16-021).

\section{Conflicts of Interest}

The authors declare no conflicts of interest regarding the publication of this paper.

\section{References}

Aerts, G., Dooms, M., \& Haezendonck, E. (2017). Knowledge Transfers and Project-Based Learning in Large Scale Infrastructure Development Projects: An Exploratory and Comparative Ex-Post Analysis. International Journal of Project Management, 35, 224-240. https://doi.org/10.1016/j.ijproman.2016.10.010

Ahn, J. G., \& Kim, J. H. (2019). Status and Role of Technological Knowledge Exchange Network in Regional Cluster: Performance Differences in Structural Equivalent Groups. Journal of Technology Innovation, 27, 53-82. https://doi.org/10.14386/SIME.2019.27.3.53

Anthony, E. M. (1963). Approach, Method and Technique. English Language Teaching, 17, 63-67. https://doi.org/10.1093/elt/XVII.2.63

Awang, A. H., Hussain, M. Y., \& Malek, J. A. (2009). Promoting Knowledge Transfer in Science and Technology: A Case Study of Technology Park Malaysia (TPM). Croatian Economic Survey, 11, 95-113.

Baker, J. (2012). The Technology-Organization-Environment Framework. In Information Systems Theory (pp. 231-245). Berlin: Springer. https://doi.org/10.1007/978-1-4419-6108-2 12

Balboni, B., Marchi, G., \& Vignola, M. (2017). Knowledge Transfer in the Context of Buyer-Supplier Relationship: An Analysis of a Supplier's Customer Portfolio. Journal of Business Research, 80, 277-287. https://doi.org/10.1016/j.jbusres.2017.06.022

Ciabuschi, F., Kong, L., \& Su, C. (2017). Knowledge Sourcing from Advanced Markets Subsidiaries: Political Embeddedness and Reverse Knowledge Transfer Barriers in Emerging-Market Multinationals. Industrial and Corporate Change, 26, 311-332. https://doi.org/10.1093/icc/dtx001

Cowan, R., \& Jonard, N. (2004). Network Structure and the Diffusion of Knowledge. Journal of Economic Dynamics and Control, 28, 1557-1575.

https://doi.org/10.1016/j.jedc.2003.04.002

Cummings, J. L., \& Teng, B. S. (2003). Transferring R\&D Knowledge: The Key Factors 
Affecting Knowledge Transfer Success. Journal of Engineering and Technology Management, 20, 39-68. https://doi.org/10.1016/S0923-4748(03)00004-3

Ganguly, A., Talukdar, A., \& Chatterjee, D. (2019). Evaluating the Role of Social Capital, Tacit Knowledge Sharing, Knowledge Quality and Reciprocity in Determining Innovation Capability of an Organization. Journal of Knowledge Management, 23, 1105-1135. https://doi.org/10.1108/JKM-03-2018-0190

Gilbert, M., \& Cordey-Hayes, M. (1996). Understanding the Process of Knowledge Transfer to Achieve Successful Technological Innovation. Technovation, 16, 301-312. https://doi.org/10.1016/0166-4972(96)00012-0

Guichard, J. (2001). A Century of Career Education: Review and Perspectives. International Journal for Educational and Vocational Guidance, 1, 155-176. https://doi.org/10.1023/A:1012207018303

Haesebrouck, K., Cools, M., \& Van den Abbeele, A. (2018). Status Differences and Knowledge Transfer: The Effect of Incentives. The Accounting Review, 93, 213-234. https://doi.org/10.2308/accr-51765

Holste, J. S., \& Fields, D. (2010). Trust and Tacit Knowledge Sharing and Use. Journal of Knowledge Management, 14, 128-140. https://doi.org/10.1108/13673271011015615

Joia, L. A., \& Lemos, B. (2010). Relevant Factors for Tacit Knowledge Transfer within Organisations. Journal of Knowledge Management, 14, 410-427. https://doi.org/10.1108/13673271011050139

Kim, S., Chang, S., \& Castro-Lacouture, D. (2020). Dynamic Modeling for Analyzing Impacts of Skilled Labor Shortage on Construction Project Management. Journal of Management in Engineering, 36, Article ID: 04019035. https://doi.org/10.1061/(ASCE)ME.1943-5479.0000720

Kuang, L., Huang, N., Hong, Y., \& Yan, Z. (2019). Spillover Effects of Financial Incentives on Non-Incentivized User Engagement: Evidence from an Online Knowledge Exchange Platform. Journal of Management Information Systems, 36, 289-320. https://doi.org/10.1080/07421222.2018.1550564

Levitt, B., \& March, J. G. (1988). Organizational Learning. Annual Review of Sociology, 14, 319-338. https://doi.org/10.1146/annurev.so.14.080188.001535

Lin, M., \& Li, N. (2010). Scale-Free Network Provides an Optimal Pattern for Knowledge Transfer. Physica A: Statistical Mechanics and Its Applications, 389, 473-480. https://doi.org/10.1016/j.physa.2009.10.004

Muñoz, C. A., Mosey, S., \& Binks, M. (2015). The Tacit Mystery: Reconciling Different Approaches to Tacit Knowledge. Knowledge Management Research \& Practice, 13, 289-298. https://doi.org/10.1057/kmrp.2013.50

Nonaka, I., Toyama, R., \& Konno, N. (2000). SECI, Ba and Leadership: A Unified Model of Dynamic Knowledge Creation. Long Range Planning, 33, 5-34. https://doi.org/10.1016/S0024-6301(99)00115-6

Pérez-Luño, A., Alegre, J., \& Valle-Cabrera, R. (2019). The Role of Tacit Knowledge in Connecting Knowledge Exchange and Combination with Innovation. Technology Analysis \& Strategic Management, 31, 186-198. https://doi.org/10.1080/09537325.2018.1492712

Rahim, F. A. M., Yusoff, N. S. M., Chen, W., Zainon, N., Yusoff, S., \& Deraman, R. (2016). The Challenge of Labour Shortage for Sustainable Construction. Planning Malaysia, 14, 77-88. https://doi.org/10.21837/pmjournal.v14.i5.194

Suppiah, V., \& Sandhu, M. S. (2011). Organisational Culture's Influence on Tacit Knowledge-Sharing Behaviour. Journal of Knowledge Management, 15, 462-477. 
https://doi.org/10.1108/13673271111137439

Tallman, S., Jenkins, M., Henry, N., \& Pinch, S. (2004). Knowledge, Clusters, and Competitive Advantage. Academy of Management Review, 29, 258-271. https://doi.org/10.5465/amr.2004.12736089

Thisse, J. F., \& Zenou, Y. (2000). Skill Mismatch and Unemployment. Economics Letters, 69, 415-420. https://doi.org/10.1016/S0165-1765(00)00334-7

Wei, Y., \& Miraglia, S. (2017). Organizational Culture and Knowledge Transfer in Project-Based Organizations: Theoretical Insights from a Chinese Construction Firm. International Journal of Project Management, 35, 571-585. https://doi.org/10.1016/j.ijproman.2017.02.010

Xie, X., Fang, L., \& Zeng, S. (2016). Collaborative Innovation Network and Knowledge Transfer Performance: A fsQCA Approach. Journal of Business Research, 69, 5210-5215. https://doi.org/10.1016/j.jbusres.2016.04.114

Zhang, Q. (2018). Theory, Practice and Policy: A Longitudinal Study of University Knowledge Exchange in the UK. Industry and Higher Education, 32, 80-92. https://doi.org/10.1177/0950422218761500

Zhu, H. M., Zhang, S. T., \& Jin, Z. (2016). The Effects of Online Social Networks on Tacit Knowledge Transmission. Physica A: Statistical Mechanics and Its Applications, 441, 192-198. https://doi.org/10.1016/j.physa.2015.08.044 